\title{
Influencing Mechanism of Linguistic Network to Animation Performance*
}

\author{
A Perspective of Meaning Innovation
}

\author{
Chen Xuesong \\ Economics and Management School \\ Zhejiang SCI-TECH University \\ Hangzhou, China, 310018 \\ xuesong77@126.com
}

\author{
Xu Dan \\ Department of Animation \\ Zhejiang Normal University \\ Hangzhou,China, 310012 \\ spoonriver12@hotmail.com
}

\begin{abstract}
Linguistic network plays a key role in animation design innovation. With a review on linguistic network andmeaning innovation, this study presents a conceptual model about the influencing mechanism of linguistic network to animation performance through meaning innovation processes. The hypotheses are then validated, and the result suggests management solutions for firms to improve their animation performance.
\end{abstract}

Keywords_linguistic network; animation value; meaning innovation

\section{INTRODUCTION}

In 2015, 134,000 minutes of cartoon have been made in China,ranking first in quantity in the world. And the total output value reached 120 billion RMB. However, there is still a wide gap between Chinese animation industry and the developed countries'. Also in 2015, the output value of animation industry in United States was more than 200 billion US dollars. In Chinese animation market, the local original animations only have $11 \%$ of the share, and the rest is mainly occupied by the US and Japan.

How can Chinese animation firms enhance performance?To solve this problem, this paper focuses on cartoon creation and value realization. Based on linguish network and meaning innovation theory, it explores the influencing mechanism of linguish network to animation performance through meaning innovation processes. With a questionnaire survey, confirmatory factor analysis(CFA) and structure equation model(SEM) are used to empirically test. And the result suggests management solutions for firms.

\section{THEORY BACKGROUND AND CONCEPT FRAMEWORK}

\section{A. Theory Background}

How do animation firms create value? And how do they organize themselves and network?

Meaning innovation theory may be the best answer to these

This research is supported by Natural Science Foundation of Zhejiang Province (LY12G02014), and Humanities and Social Science project for Youth Scholar of Ministry of Education of China (12YJC630017, 13YJCZH210). questions. Most researchers agreed upon the importance of technology innovation. And in recent years, some researchers went one step further: they demonstrated that innovation could also come about through change in meaning. ${ }^{[1]}$

Meaning is the symbolic and emotional value in product or service. Traditionally, this role of creating breakthroughproduct meanings by acting on the semantic dimension of products was that of adesigner. ${ }^{[2-4]}$

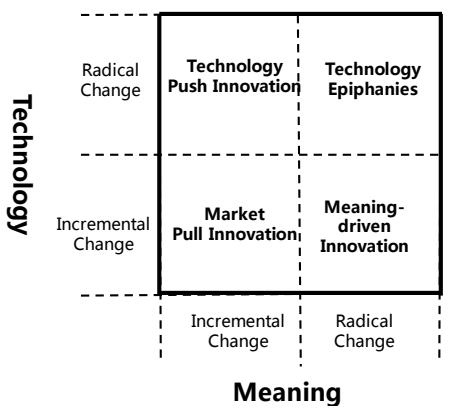

Fig. 1. The two dimensions and four types of innovation (Source: reference[11])

The framework of Figure 1 connects the two dimensions of technology and meaning, which define four types of innovations. ${ }^{[1]}$ Animation creation is driven by radical meaning change.US animation, which combine technology and meaning, is located in the 'Technology Epiphanies' interval. And Japanese animation, which is driven by socio-culture, is located in the 'meaning-driven innovation' interval.

Linguistic network is essential to meaning innovation. Theterm linguistic network means the set of actors and relationships that (1) identify,capture and interpret sociocultural trends, and (2) embed the results of these analysesinto products.Through this type of network, a firm can develop products that"speak" particular languages to meet consumer needs. Linguistic network Consists of managers, Designers, Socio-culture researchers and product developers. ${ }^{[2,3]}$

A new framework is provided to look at meaning innovation as interpreting(of developing meaningful scenarios rather than finding an optimal solution) and envisioning(of 
imaging experiences that are still not asked for, rather than answer to existing needs ) processes. ${ }^{[5]}$

\section{B. Research Hypotheses and Concept Framwork}

In the following sub-paragraph, research hypotheses are introduced to describe relationships among linguistic network, meaning innovation (interpreting and envisioning) processes and animation performance. According to meaning innovation theory and animation practice, we can regard interpreting as creating a new narrative semiotic system (world setting, characterization, etc.), and envisioning(reiterate, appropriate and even parodize in a creative way) as using this kind of system. ${ }^{[6-9]}$ Since meaning innovation processes are essential to the animation performance, there we posit the following:

H1: The firm's meaning innovation processes will have a positive effect on the animation performance.

H1a: The firm's interpreting process will have a positive effecton the animation performance.

$H 1 b$ : The firm's envisioning process will have a positive effecton the animation performance.

For interpreting process is ahead of envisioning process, there we posit the following:

H2: The firm's interpreting process will have a positive effect on the envisioning process.

According to resourced-based view, firms' resource influences the performance through the processes. And linguistic network are looked as the most important resource for meaning innovation. The position and the degree of involvement in meta project activities influence the meaning innovation processes. There we posit the following:

H3: The firm's position in Linguistic Network will have a positive effect on the meaning innovation processes of animation.

H3a: The firm's position in Linguistic Network will have a positive effecton interpreting process of animation.

H3b: The firm's position in Linguistic Network will have a positive effect onenvisioning process of animation.

H4: The firm's degree of involvement in Linguistic Network will have a positive effect on the meaning innovation processes of animation.

H4a: The firm's degree of involvement in Linguistic Network will have a positive effect oninterpreting process of animation.

$H 4 b$ : The firm's degree of involvement in Linguistic Network will have a positive effect onenvisioning process of animation.

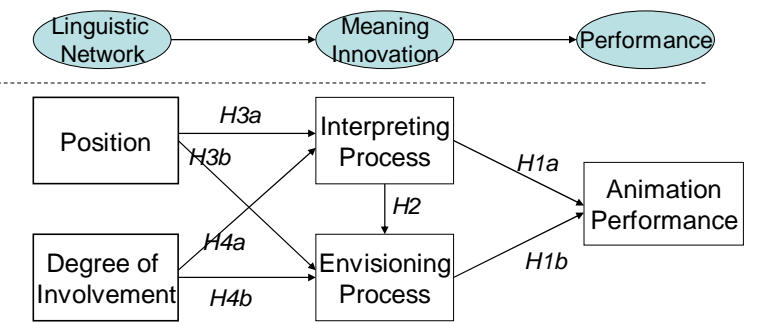

Fig. 2. Concept Framwork

The concept framework about influencing mechanism of linguistic network to animation performance is showed in Figure 2.

\section{ANALYSIS AND DISCUSSION}

\section{A. Data and Methods}

We used a survey to collect data to test our hypotheses, which were analyzed through a factor analysis and structure equation model analysis.

Anquestionnaire has been distributed among 226CEOs or chief designers of animation firms in Zhejiang Province, China. The resultsfrom the pretest showed no particular bias. The 5point Likert scales are hired in the questionnaire. We revisedthe data of these items accordingly. Cronbach'salphas were calculated, and all of them exceeded the recommendedgood reliability level of 0.80 .

\section{B. Measures and CFA results}

We first conducted a confirmatory factor analysis (CFA) using AMOS 21.0 to determine the validity and reliability of our measures. The factor loadings for each individual indicator on their respective constructs were all statistically significant $(\mathrm{P}<0.01)$, establishing convergent validity. Since our research contain several mulita-item scales, we investigated the psychometric properties of the measures through the composite reliability index and average variance extracted the recommended benchmarks of 0.70 , respectively(Table 1 ).

TABLE I. MEASUREMENT MODEL RESULTS

\begin{tabular}{|c|c|c|c|}
\hline Construct & measurement items & AVE & CR \\
\hline \multirow{4}{*}{$\begin{array}{l}\text { Position in } \\
\text { Linguistic } \\
\text { Network }\end{array}$} & Density of network & \multirow{4}{*}{0.82} & \multirow{4}{*}{0.75} \\
\hline & Size of network & & \\
\hline & Centrility of network & & \\
\hline & Structure Holes & & \\
\hline \multirow{3}{*}{$\begin{array}{l}\text { Degree of } \\
\text { involvement } \\
\text { in Linguistic } \\
\text { Network }\end{array}$} & Strenght of relationship & \multirow{3}{*}{0.91} & \multirow{3}{*}{0.77} \\
\hline & Stability of relationship & & \\
\hline & Trust of relationship & & \\
\hline \multirow{3}{*}{$\begin{array}{l}\text { Interpreting } \\
\text { Process }\end{array}$} & Socio-culture context recognition & \multirow{3}{*}{0.88} & \multirow{3}{*}{0.72} \\
\hline & Design scenarios of meaning & & \\
\hline & Debating & & \\
\hline \multirow{3}{*}{$\begin{array}{l}\text { Envisioning } \\
\text { Process }\end{array}$} & Building critical capability & \multirow{3}{*}{0.79} & \multirow{3}{*}{0.80} \\
\hline & Envisioning new meaning & & \\
\hline & New technology application & & \\
\hline \multirow{4}{*}{$\begin{array}{l}\text { Animation } \\
\text { Performance }\end{array}$} & Sales & \multirow{4}{*}{0.84} & \multirow{4}{*}{0.82} \\
\hline & Profit & & \\
\hline & Reputation & & \\
\hline & Award & & \\
\hline
\end{tabular}




\section{RESUltS}

\section{A. Structural model analysis}

Given the results of the measurement model assessment, wenext examined a structural model. The results are summarizedin Fig. 2. The fit indices for the overall model were asfollows: $\quad x{ }^{2}=502.5$, CFI $=0.92$, RMSEA $=0.08$, TFI $=0.91$, IFI $=0.93$. Thesevalues collectively indicate that the structural model has anacceptable fit.

\section{B. MainPaths}

In $\mathrm{H} 1$, we hypothesize the original path of meaning innovation processes to animation performance. The coefficient of $\mathrm{H} 1 \mathrm{a}$ (interpreting process to animation performance) was statistically significant(Standard coefficients $=0.44, \mathrm{p}<0.001$ ), while The coefficient of $\mathrm{H} 1 \mathrm{~b}$ (envisioning process to animation performance) was statistically significant(Standard coefficients $=0.47, \mathrm{p}<0.001$ ). Thus, H1 was supported.

In $\mathrm{H} 2$, we hypothesize the original path of interpreting processes to envisioning process. The coefficient of $\mathrm{H} 2$ was not statistically significant(Standard coefficients $=0.19, \mathrm{p}>0.05$ ). Thus, H2 was supported.

In H3, we hypothesize the original path of position in linguisticnetwork to innovation processes. The coefficient of H3a(position in linguistic network to interpreting process) was statistically significant(Standard coefficients $=0.66, \mathrm{p}<0.001$ ), while The coefficient of $\mathrm{H} 1 \mathrm{~b}$ (position in linguistic network to envisioning process) was statistically significant(Standard coefficients $=0.24, \mathrm{p}<0.001$ ). Thus, H3 was supported.

In $\mathrm{H} 4$, we hypothesize the original path of degree of involvement in linguistic network to innovation processes. The coefficient of $\mathrm{H} 4 \mathrm{a}$ (involvement in linguistic network to interpreting process) was not statistically significant(Standard coefficients $=0.19, \mathrm{p}>0.05$ ), while The coefficient of $\mathrm{H} 1 \mathrm{~b}$ (involvement in linguistic network to envsioning process) was statistically significant(Standard coefficients $=0.44$, $\mathrm{p}<0.001)$. Thus, H4 was partly supported.

These Paths are showed in Table 2 and Figure 3.

TABLE II. STRUCTURAL MODEL RESULTS

\begin{tabular}{|c|c|c|c|c|}
\hline Paths & $\begin{array}{c}\text { Standard } \\
\text { coefficients }\end{array}$ & $S E$ & $C R$ & \\
\hline $\begin{array}{l}\text { Position in linguistic network } \\
\rightarrow \text { Interpreting process }\end{array}$ & 0.66 & 0.10 & 0.75 & $* * *$ \\
\hline $\begin{array}{l}\text { Position in linguistic network } \\
\rightarrow \text { Envisioning process }\end{array}$ & 0.24 & 0.09 & 4.56 & $* * *$ \\
\hline $\begin{array}{l}\text { Degree of involvement in } \\
\text { liguistic network } \\
\rightarrow \text { Interpreting process }\end{array}$ & 0.19 & 0.08 & 1.19 & n.s \\
\hline $\begin{array}{l}\text { Degree of involvement in } \\
\text { linguistic network } \\
\rightarrow \text { Envisioning process }\end{array}$ & 0.44 & 0.11 & 4.42 & $* * *$ \\
\hline $\begin{array}{l}\text { Interpreting process } \\
\rightarrow \text { Animation Performance }\end{array}$ & 0.44 & 0.09 & 6.44 & $* * *$ \\
\hline $\begin{array}{l}\text { Envisioning process } \\
\rightarrow \text { Animation Performance }\end{array}$ & 0.47 & 1.09 & 5.23 & $* * *$ \\
\hline $\begin{array}{l}\text { Interpreting process } \\
\rightarrow \text { Envisioning process }\end{array}$ & 0.07 & 0.08 & 1.52 & n.s \\
\hline
\end{tabular}

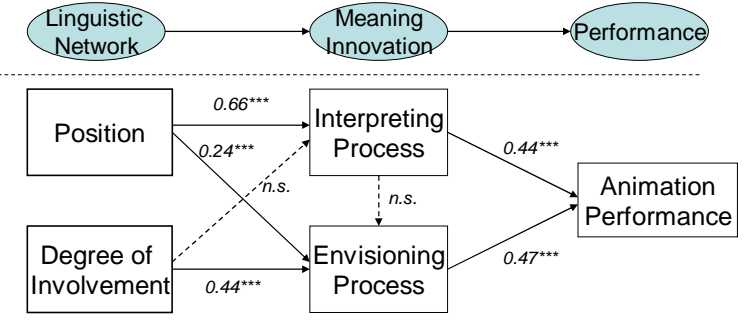

Fig. 3. Structural Model Results

Note: $* * \mathrm{p}<0.05, * * * \mathrm{p}<0.01$, n.s. no signigicant

\section{CONCLUSION}

\section{A. Implications for research and practice}

This study makes an important contribution to the animation industry theory, by claiming that the role of meaning innovation processesplays a key role in animation performance. Our model is an extension of linguistic network theory. Based on the results obtained from 226 animation firms, we attempt to draw the following implication.

Theoretically, our hypotheses testing results clearly supported the influencing mechanism of linguistic network to animation performance through meaning innovation processes. There are three paths to improve animation performance. They are position in linguistic network $\rightarrow$ interpreting process $\rightarrow$ animation performance(Path 1), position in linguistic network $\rightarrow$ envisioning process $\rightarrow$ animation performance(Path 2 ), and Degree of involvement in linguistic network $\rightarrow$ interpreting process $\rightarrow$ animation performance(Path 3 ).

In today's China, a lot of animation firms try to enhance their performance in Path 3. The result shows that they should pay more attention on Path 1 and 2, which help improve their interpreting capability.

The result also suggests that open society is necessary for amination performance. As noted above, the debating and critical capability only can be improved in the open society. And Government plays a key role of encouraging the firms to share their knowledge in the linguistic network.

\section{B. Limitation and further research}

This study has some limitation.Firstly and foremost, our scale may not have captured allnecessary elements of the linguistic network and meaning innovation concept. In this respect, further research should attempt to develop a measurementthat captures the full scope of dimensions such as cognitive consistency in linguistic network.Secondly, ourrespondents provided data for both independent anddependent variables. Studiesemploying single-source methodology may be biased byartificially high intercorrelations, because of an overallpositive or negative response bias. Further research shouldseek multi-source data.Thirdly, this study focuses on the linguistic network outside of the firms. Future research should pay more attention on the actors network inside of the firm. Finally, case studies should be adopted in the future. 


\section{ACKNOWLEDGMENT}

This research is supported by Natural Science Foundation of ZhejiangProvince(LY12G0201, 'Evolution of Firms’ Deign Capability, a Perspective of knowledge Network Embeddedness.'), and Humanities and Social Science project for Youth Scholar of Ministry of Education of China (12YJC630017,'Influencing Mechanism of Knowledge Network Embeddedness to Firms' Design Innovation Capability.'; 13YJCZH210,'Formation Mechanism of Animation Brand Images, a Perspective of Discourse Theory.’).

\section{REFERENCES}

[1] Norman D A, Verganti R. Incremental and radical innovation: Design research vs. technology and meaning change[J]. Design Issues, 2014,30(1):78-96.

[2] Verganti R. Design-driven innovation: Changing the rules of competition by radically innovating what things mean[M]. Boston: Harvard Business Press, 2009.
[3] Dell'Era C, Marchesi A, Verganti R. LINGUISTIC NETWORK CONFIGURATIONS:: MANAGEMENT OF INNOVATION IN DESIGN-INTENSIVE FIRMS[J]. International Journal of Innovation Management, 2008,12(1):1-19.

[4] Verganti R. Innovating Through DESIGN.[J]. Harvard Business Review, 2006,84(12):114-122.

[5] Verganti R, Öberg Å. Interpreting and envisioning-A hermeneutic framework to look at radical innovation of meanings[J]. Industrial Marketing Management, 2013,42(1):86-95.

[6] Cohn N. Building a better comic theory: Shortcomings of theoretical research on comics and how to overcome them[J]. Studies in Comics, 2014,5(1):57-75.

[7] Singer M. The myth of Eco: Cultural populism and comics studies[J]. Studies in Comics, 2013,4(2):355-366.

[8] Bateman John A, Veloso Francisco O. D. The semiotic resources of comics in movie adaptation: Ang Lee' s Hulk (2003) as a case study[J]. Studies in Comics, 2013,4(1):135-157.

[9] Chao T. Transmutation of worlds: Adaptation and transformation in Fullmetal Alchemist the Movie: Conqueror of Shamballa[J]. Studies in Comics, 2013,4(1):159-170. 